\title{
Effects of the Atomic Number of Alkali Atom and Pore Size of Graphyne on the Second Order Nonlinear Optical Response of Superalkali Salts of Graphynes $\mathrm{OM}_{3}{ }^{+} @ \mathrm{GYs}^{-}(\mathrm{M}=\mathrm{Li}$, Na, and $\mathrm{K})$
}

\author{
Na Hou ${ }^{1}$, Fang Yue $\mathrm{Du}^{1}$, Ran Feng ${ }^{1}$, Hai Shun $\mathrm{Wu}^{1}$, and Zhi-Ru $\mathrm{Li}^{2}$ \\ ${ }^{1}$ Shanxi Normal University \\ ${ }^{2}$ Jilin University
}

June 17, 2020

\begin{abstract}
Based on the combination of novel carbon material graphynes (GYs) and superalkalis $\left(\mathrm{OM}_{3}\right)$, a class of graphyne superalkali complexes, $\mathrm{OM}_{3}+@(\mathrm{GY} / \mathrm{GDY} / \mathrm{GTY})^{-}(\mathrm{M}=\mathrm{Li}, \mathrm{Na}$, and $\mathrm{K})$, have been designed and investigated by density functional theory method. Computational results reveal that these complexes with high stability can be regarded as novel superalkali salts of graphynes due to electron transfer from $\mathrm{OM}_{3}$ to GYs. For second order nonlinear optical response, these superalkali salts exhibit large first hyperpolarizabilities $\left(\beta_{0}\right)$. Two important effects on $\beta_{0}$ values are found, namely the atomic number of alkali atom in superalkali and the pore size of graphyne. Integrating the two effects, the selected combination of OLi3 with large pore size GTY can bring the considerable $\beta_{0}$ value $\left(6.5 \times 10^{5} \mathrm{au}\right)$, which is a new record for superatom-doped graphynes. In the resulting complex, the $\mathrm{OLi}_{3}$ molecule is located at the center of the pore of GTY, forming a planar structure with the highest stability among these salts. Besides large $\beta_{0}$ values, these superalkali salts of graphynes have deep-ultraviolet working region, hence can be considered as a new kind of high-performance deep-ultraviolet NLO molecules.
\end{abstract}

\section{INTRODUCTION}

During the past decades, people have paid great efforts to explore more high-performance nonlinear optical (NLO) materials because of their wide applications in the field of information processing, photoelectric, optical data storage and many others. ${ }^{1-7}$ Currently, numerous types of molecules with large NLO response have been studied, including structures of the donor- $\pi$ bridge-acceptor type, ${ }^{8,9}$ the transition metal-ligand structures, ${ }^{10,11}$ and complexes with loosely bound excess electron. ${ }^{12,13}$ In 2004 , Li et al. reported that the molecular cluster anions $(\mathrm{FH})_{2}\{\mathrm{e}\}(\mathrm{HF})$ and $\left(\mathrm{H}_{2} \mathrm{O}\right)_{3}\{\mathrm{e}\}$ with excess electron exhibited significantly large nonlinear optical responses. ${ }^{14,15}$ This opens up a new direction for designing novel compounds with considerable NLO properties. These novel compounds are a class of nontraditional ionic salts, named electrides, where the anionic sites are occupied solely by electrons. ${ }^{16}$ Studies have shown that alkali metal doping is one of the most common methods for designing electrides. ${ }^{12}$ Recently, the use of superalkalis instead of alkali atoms to design new electrides with larger hyperpolarizabilities $\left(\beta_{0}\right)$ has attracted much attention. ${ }^{17,18}$

Superalkalis ${ }^{19}$ are a well-known class of superatoms ${ }^{20}$ that possess lower ionization potential (IP) values than alkali metal atoms, thus their valence electrons are more likely to be polarized by ligands and form loosely bound excess electrons. Therefore, the interaction of superalkali with appropriate ligands can generate more diffuse excess electron, leading to new superalkali-doped systems with larger NLO response.

Although the excess electron generated by the polarization of organic ligands can greatly increase the $\beta_{0}$ value of a molecular system, the presence of the loosely bound excess electrons makes the thermal stability of the molecule unsatisfactory. Besides, NLO materials in the infrared and deep-ultraviolet (deep-UV) working 
wavebands are currently the research hotspots. ${ }^{3}$ Consequently, finding a system with high stability, large hyperpolarizability and working area in the infrared or deep-ultraviolet regions has become an important research topic in the field of NLO.

Recently, new two-dimensional carbon allotrope-graphynes with special structural features and thermal stability have attracted the interest of many researchers from different areas. As early as 1987, Baughman et al. ${ }^{21}$ first proposed that graphynes (GYs) are a series of one atom thick carbon allotropes composed of sp- and $\mathrm{sp}^{2}$-hybridized carbon atoms. Two hybridization states of carbon atoms enable GYs to have many excellent properties, including extended $\pi$-conjugation, uniformly distributed pores, tunable electronic properties, good chemical stability and large surface area. ${ }^{22,23}$ Four main types of graphyne namely $a-, \beta-, \gamma-$, and $6,6,12$-graphynes have been identified. ${ }^{21} \gamma$-graphyne is the most widely studied form of GYs, especially graphdiyne (GDY), which is formed by the self-assembly of hexagonal rings and acetylenic groups and has a largely delocalized $\pi$-conjugated surface. Although many scientists have attempted to prepare GYs, it was not until 2010 that Li's group successfully synthesized large-area films of graphdiyne on a copper substrate via a cross-coupling reaction. ${ }^{24}$ Due to the fascinating structures and particular electronic properties, graphyne materials show promising applications in catalysts, hydrogen storage, anode materials, optoelectronic devices, biomedicine and therapy, etc . ${ }^{22,23,25-29}$

More interestingly, the graphyne molecules have recently aroused extensive attention of theoretical researchers in the field of nonlinear optics. In 2016, Chakraborti ${ }^{30}$ theoretically investigated the NLO properties of donor-acceptor substituted graphyne structures. In the same year, the hyperpolarizabilities of graphdiyne functionalized by the alkali metal atom etc . were investigated. ${ }^{31}$ Very recently, Li et al. designed a variety of promising novel GDY-based NLO materials. ${ }^{32-35}$ Instead of replacing hydrogen of GDY with alkali metal atom, ${ }^{31} \mathrm{Li}$ et al. theoretically confirms that alkali atom doping is a viable approach to increase the $\beta_{0}$ value of GDY. ${ }^{32,33}$ Besides, superalkaline-earth metal $\mathrm{M}_{3} \mathrm{~F}(\mathrm{M}=\mathrm{Li}, \mathrm{Na}$, and $\mathrm{K})$, and superalkali $\mathrm{Li}_{3} \mathrm{NM}$ and $\mathrm{M}_{2} \mathrm{X}$ $(\mathrm{M}=\mathrm{Li}, \mathrm{Na}, \mathrm{K}$ and $\mathrm{X}=\mathrm{F}, \mathrm{Cl}, \mathrm{Br})$ can also be adsorbed on the GDY surface, respectively, to produce new complexes with large $\beta$ ovalues. ${ }^{34-36}$ Thus, the GDY and superalkaline-earth metal/superalkali would be a good combination for designing novel NLO materials.

Considering characteristics of GYs including thermal stability, deep-ultraviolet transparency, and large pores, we have designed a series of superalkali salts of graphynes, namely $\mathrm{OM}_{3}+@ \mathrm{GYs}^{-}(\mathrm{M}=\mathrm{Li}, \mathrm{Na}$, and $\mathrm{K}$; GYs include GY, GDY, and GTY) in the present work. Figure 1 shows the graphyne structure consists of hexagons connected by acetylenic $(-\mathrm{C}[?] \mathrm{C}-)$ rather than cumulative $(=\mathrm{C}=\mathrm{C}=)$ linkages. ${ }^{37}$ According to the number of acetylenic linkers (-C[?]C-), GYs can be classified into GY, GDY, and GTY. These representative structural models of delocalized $\pi$-conjugated graphynes were chosen here to combine with superalkalis $\left(\mathrm{OLi}_{3}, \mathrm{ONa}_{3}\right.$, and $\left.\mathrm{OK}_{3}\right)$ to generate a new series of complexes. Note that these superalkalis have been experimentally synthesized, ${ }^{38-40}$ and they can serve as basic building blocks for new complexes. ${ }^{41-44}$ The evolution of their first hyperpolarizability with varying superalkali atom and pore size of graphyne has been analyzed in order to explore new high-performance NLO molecules. The structures, stability, and static first hyperpolarizabilities of the investigated complexes are explored by employing density functional theory (DFT). The frontier molecular orbital and atomic charge analyses indicate that $\mathrm{OM}_{3}+@ \mathrm{GYs}^{-}$have superalkali salt characteristics. Two influencing factors on $\beta_{0}$ values, namely the atomic number of alkali atom $\mathrm{M}$ and pore size of graphyne, are discussed in detail. Results show that the combination of $\mathrm{OLi}_{3}$ and GTY (with a large pore) forms a planar stable structure possessing the largest $\beta$ o up to $6.5 \times 10^{5}$ au. This work proposes a new kind of high-performance deep-UV NLO molecules. It is extremely expected that this research can attract more experimental interest in designing novel carbon-based NLO materials in the near future.

\section{COMPUTATIONAL DETAILS}

The Becke's three-parameter hybrid exchange functional with the Lee-Yang-Parr correlation functional (B3LYP) was reported to perform well for the calculation of alkali metal-adsorbed graphdiyne structures. ${ }^{32,33}$ In this work, the optimization and frequency analysis for all the geometrical structures were performed at the B3LYP/6-31+G(d) level. Merz-Kollman (MK) charges, ${ }^{45}$ vertical ionization potentials 
(VIP), and interaction energies ( $E$ int $)$ of the superalkali-doped graphynes were evaluated at the same level based on the optimized geometries. The VIP is defined as the total energy difference between the cationic and neutral compound with the same geometry as the neutral compound. The counterpoise $(\mathrm{CP})$ procedure $^{46}$ was applied in interaction energy calculation to eliminate the basis set superposition error (BSSE). That is, the $E$ int is computed according to:

$E_{\text {int }}=E_{\mathrm{AB}}\left(\chi_{\mathrm{AB}}\right)-E_{A}\left(\chi_{\mathrm{AB}}\right)-E_{B}\left(\chi_{\mathrm{AB}}\right)(1)$

where the same basis set, $\chi_{A B}$, is used for both the monomer energy calculations $\left(E_{A}\right.$ and $\left.E_{B}\right)$ and the complex energy $\left(E_{A B}\right)$ calculation.

Previous studies have shown that a new density functional Coulomb-attenuated hybrid exchange-correlation functional (CAM-B3LYP $)^{47,48}$ can provide more reasonable and accurate predictions for the evaluation of the NLO properties. ${ }^{31,35,49}$ Furthermore, the values of first hyperpolarizability $\left(\beta_{0}\right)$ are quite sensitive to the basis set used. Therefore, taking $\mathrm{OLi}_{3} @$ GDY as an example, the test calculations for basis set effect are shown in Figure 2. Results showed that the dispersion basis set greatly influenced the first hyperpolarizability. The result obtained with the medium-sized $6-31+\mathrm{G}(\mathrm{d})$ basis set was very close to those with the other dispersion basis sets and much larger with respect to that with $6-31 \mathrm{G}(\mathrm{d})$. Therefore, the $6-31+\mathrm{G}(\mathrm{d})$ basis set was chosen to calculate the $\beta_{0}$ values of all the complexes in this study.

The total energy of a molecular system in the weak and homogeneous electric field can be expressed as:

$E=E_{0}-\mu_{i} F_{i}-\frac{1}{2 !} \alpha_{\mathrm{ij}} F_{i} F_{j}-\frac{1}{3 !} \beta_{\mathrm{ijk}} F_{i} F_{j} F_{k}+(2)$

where $E_{0}$ is the system energy in the absence of an electric field; $F_{i}$ is the Cartesian component of the applied electric field along the $i$ direction; $\mu_{\imath}, a_{\imath \vartheta}$, and $\beta_{\imath \vartheta \kappa}$ are the permanent dipole moment, polarizability, and first hyperpolarizability tensors, respectively; and $i, j$, and $k$ designate the different components along the $x, y$, and $z$ directions, respectively. The static first hyperpolarizability $\left(\beta_{0}\right)$ is expressed as:

$\beta_{0}=\left(\beta_{x}^{2}+\beta_{y}^{2}+\beta_{z}^{2}\right)^{\frac{1}{2}}(3)$

where $\beta_{i}=\left(\frac{1}{3}\right) \sum_{j}\left(\beta_{\mathrm{ijj}}+\beta_{\mathrm{jji}}+\beta_{\mathrm{jij}}\right), \quad i, j=\{x, y, z\}$.

It is known that the time-dependent density functional theory (TD-DFT) method is one of the most widely used methods to calculate the excitation energies owing to its efficiency and accuracy. Thus, crucial excited states and ultraviolet-visible (UV-vis) absorption spectrums of the related systems were obtained by means of the TD-CAM-B3LYP method in conjunction with the $6-31+\mathrm{G}(\mathrm{d})$ basis set.

All the above calculations were carried out using the Gaussian 09 program package. ${ }^{50}$ The dimensional plots of molecular geometries and molecular orbitals were generated with the GaussView program. ${ }^{51}$ The hyperpolarizability density diagrams were obtained by employing the Multiwfn 3.7 (dev) $\operatorname{code}^{52}$ and Visual Molecular Dynamics (VMD) software. ${ }^{53}$ 


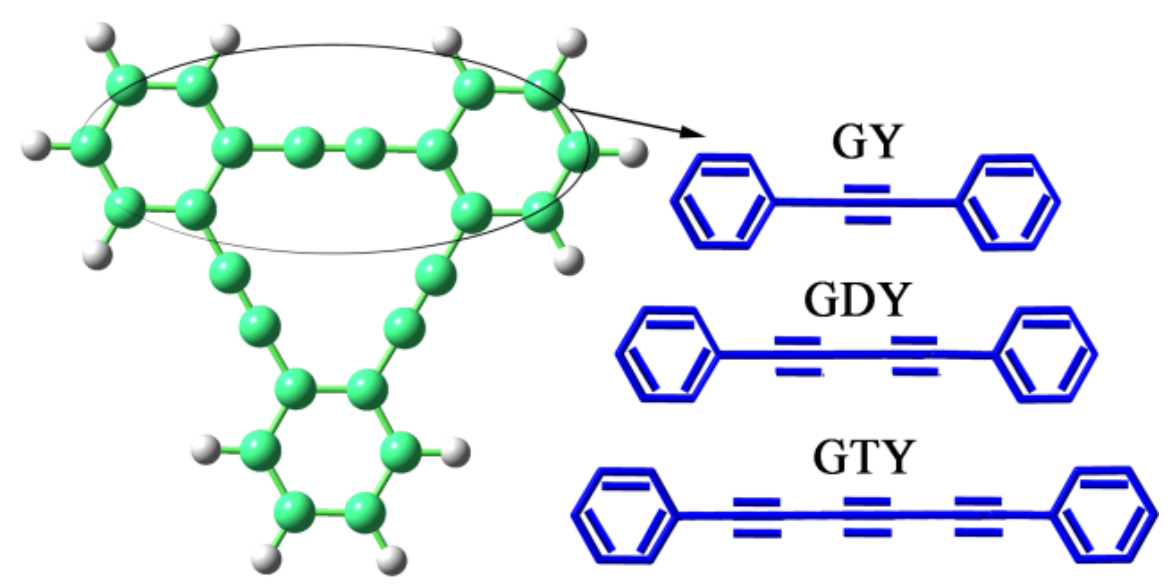

FIGURE 1 Representation of three models of the graphyne structures (GY, GDY, and GTY)

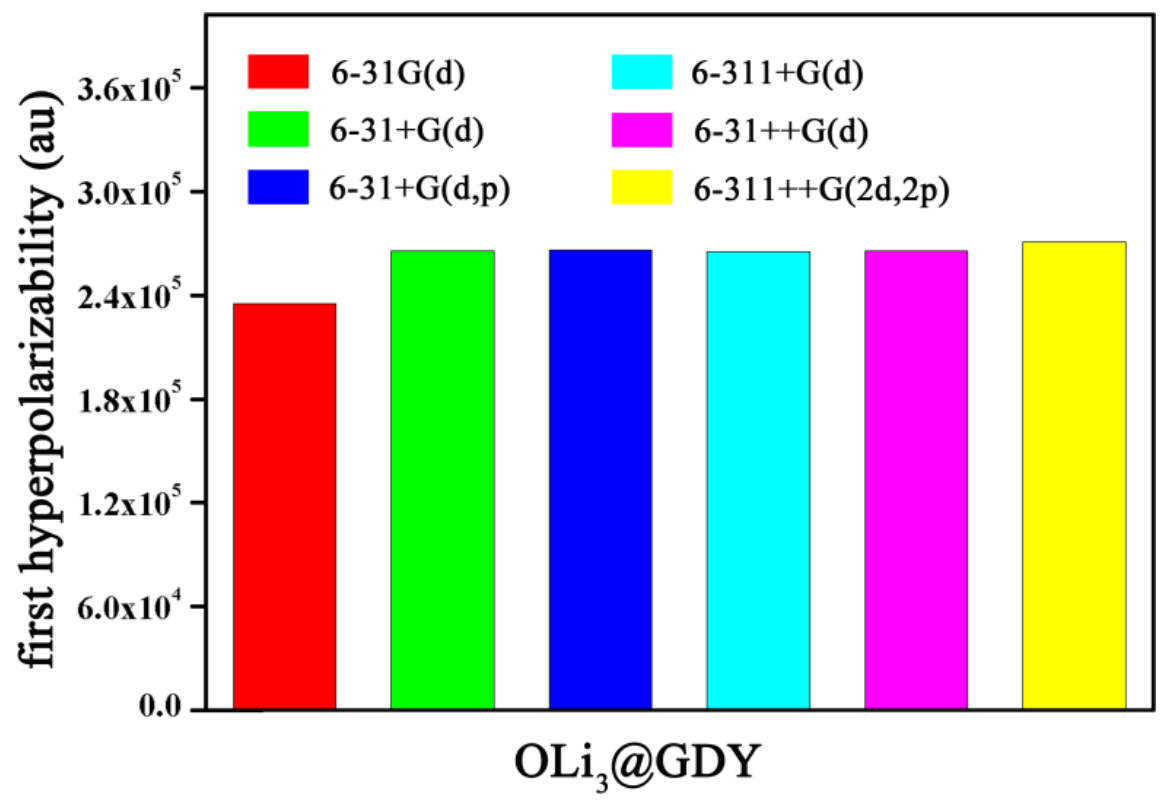

FIGURE 2 The static first hyperpolarizability of OLi $3 @$ GDY calculated at the CAM-B3LYP level with different basis sets

\section{RESULTS AND DISCUSSION}

\subsection{Structural Characteristics}

The geometrical structures of superalkali $\mathrm{OM}_{3}$ doped GYs (GY, GDY, and GTY) were systematically investigated using density functional method. To search for the most stable structure of the resulting complexes, we considered all the possible interaction orientations between $\mathrm{OM}_{3}$ and GYs. The top and side views of the stable structures of the $\mathrm{OM}_{3} @ \mathrm{GYs}(\mathrm{M}=\mathrm{Li}, \mathrm{Na}$, and $\mathrm{K})$ complexes are displayed in Figure 3. In the case of $\mathrm{OLi}_{3} @ \mathrm{GY}$, the $\mathrm{OLi}_{3}$ unit is located above the central pore of GY and the three Li atoms are close to three $-\mathrm{C}[?] \mathrm{C}-$ units, respectively. $\mathrm{ONa}_{3} @ \mathrm{GY}$ and $\mathrm{OK}_{3} @ \mathrm{GY}$ possess similar geometric features, in which superalkali $\mathrm{OM}_{3}$ deviates from the central position of the pore and one of the $\mathrm{Na} / \mathrm{K}$ atoms tends to approach one of the benzene rings. It can be seen that the GY 

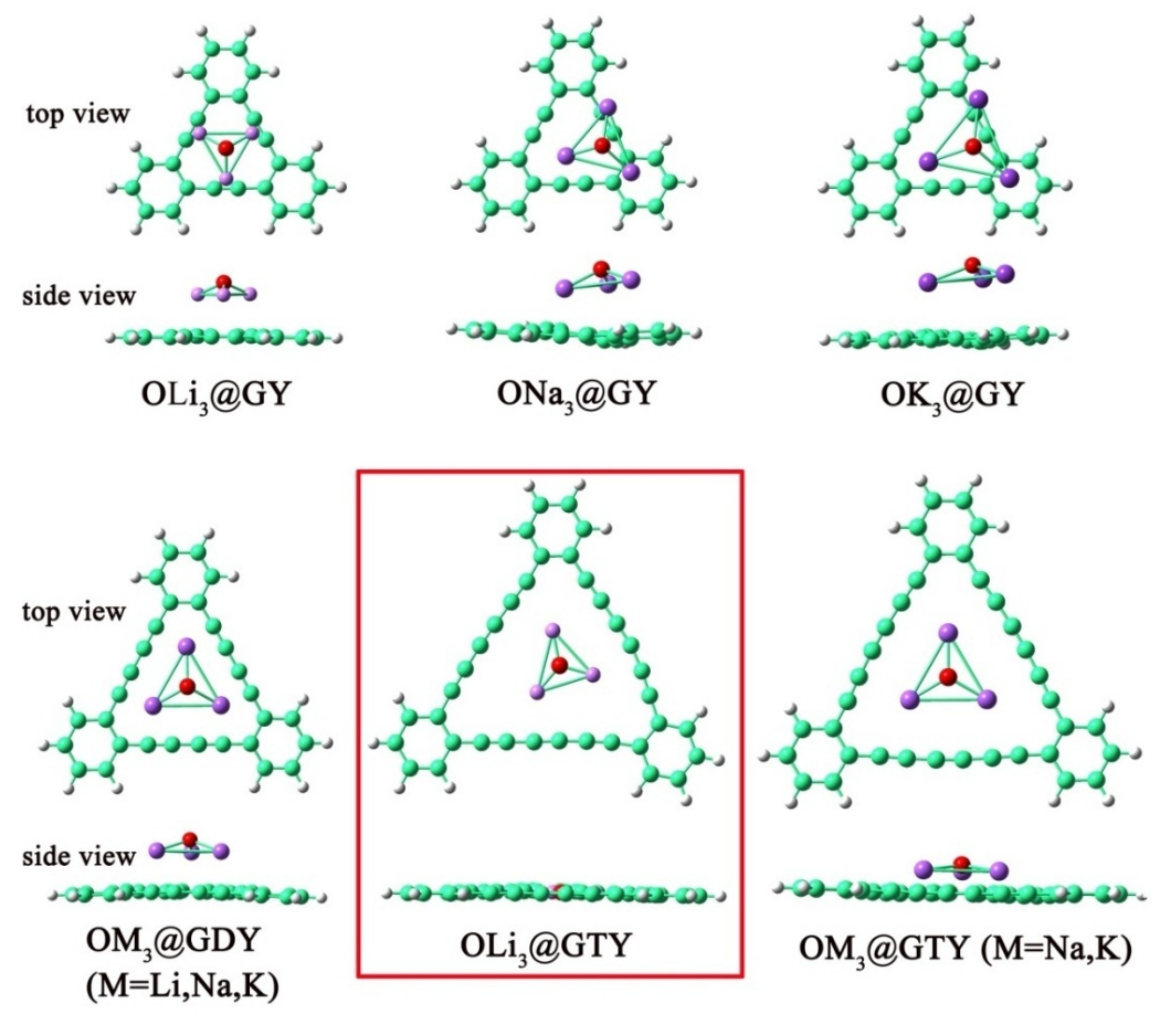

FIGURE 3 Optimized structures of $\mathrm{OM}_{3} @(\mathrm{GY} / \mathrm{GDY} / \mathrm{GTY})(\mathrm{M}=\mathrm{Li}, \mathrm{Na}$, and $\mathrm{K})$

unit of $\mathrm{OM}_{3} @ \mathrm{GY}(\mathrm{M}=\mathrm{Li}, \mathrm{Na}$, and $\mathrm{K})$ exhibits a slight corrugation, especially for $\mathrm{ONa}_{3} @ \mathrm{GY}$. In contrast, the $\mathrm{OM}_{3}$ units in $\mathrm{OM}_{3} @ \mathrm{GDY}(\mathrm{M}=\mathrm{Li}, \mathrm{Na}$, and $\mathrm{K})$ are all above the central position of the pore and the three alkali atoms point to three benzene rings, respectively. It is clearly seen that the structural features of $\left(\mathrm{ONa}_{3} / \mathrm{OK}_{3}\right) @ \mathrm{GTY}$ are similar to those of $\mathrm{OM}_{3} @ \mathrm{GDY}$. Interestingly, unlike other structures, small-sized $\mathrm{OLi}_{3}$ is embedded inside the large pore of GTY, which leads to a planar structure of $\mathrm{OLi}_{3} @ \mathrm{GDY}$, as shown in red box in Figure 3. Except for $\mathrm{OLi}_{3}$ in $\mathrm{OLi}_{3} @ \mathrm{GTY}$, all the other $\mathrm{OM}_{3}$ units distort from a triangle to an umbrella shape. Table 1 shows that average $\mathrm{O}-\mathrm{M}$ bonds of the $\mathrm{OM}_{3}$ unit in $\mathrm{OM}_{3} @(\mathrm{GY} / \mathrm{GDY} / \mathrm{GTY})$ are slightly elongated compared with the corresponding $\mathrm{O}-\mathrm{Li}$ (1.683), O-Na (2.053), and O-K (2.404 $\AA$ ) bonds in isolated $\mathrm{OM}_{3}$. This indicates that the interaction between $\mathrm{OM}_{3}$ and GYs has little impact on the M-O chemical bonds. The vertical distance $(d)$ between $\mathrm{OM}_{3}$ and the graphyne surface (GY, GDY, and GTY) is also given in the table, which exhibits an increasing trend with increasing atomic number of M.

TABLE 1 The average $\mathrm{O}-\mathrm{M}$ bond lengths $R{ }_{\mathrm{O}-\mathrm{M}}(\AA)$, vertical distances between the $\mathrm{O}$ atom and plane $d(\AA)$, interaction energies $E$ int $\left(\mathrm{kcal} \mathrm{mol}^{-1}\right)$, MK charges on the $\mathrm{OM}_{3}$ units $q(|e|)$, and vertical ionization potentials VIP $(\mathrm{eV})$ of the $\mathrm{OM}_{3} @ \mathrm{GYs}(\mathrm{M}=\mathrm{Li}, \mathrm{Na}$, and $\mathrm{K})$

\begin{tabular}{llllll}
\hline System & $R_{\mathrm{O}-\mathrm{M}}$ & $d$ & $E_{\text {int }}$ & $q$ & VIP \\
\hline $\mathrm{OLi}_{3} @ G Y$ & 1.692 & 2.847 & -47.18 & 0.530 & 4.79 \\
$\mathrm{ONa}_{3} @ G Y$ & 2.075 & 3.017 & -34.97 & 0.588 & 4.60 \\
$\mathrm{OK}_{3} @ \mathrm{GY}$ & 2.416 & 3.316 & -36.52 & 0.680 & 4.27 \\
$\mathrm{OLi}_{3} @ \mathrm{GDY}$ & 1.686 & 1.996 & -53.00 & 0.473 & 4.61 \\
$\mathrm{ONa}_{3} @ G D Y$ & 2.060 & 2.866 & -36.54 & 0.589 & 4.52 \\
$\mathrm{OK}_{3} @ G D Y$ & 2.409 & 3.429 & -39.13 & 0.666 & 4.25
\end{tabular}




\begin{tabular}{llllll}
\hline System & $R_{\mathrm{O}-\mathrm{M}}$ & $d$ & $E_{\text {int }}$ & $q$ & VIP \\
\hline $\mathrm{OLi}_{3} @ \mathrm{GTY}$ & 1.693 & 0.000 & -61.15 & 0.485 & 4.83 \\
$\mathrm{ONa}_{3} @ \mathrm{GTY}$ & 2.056 & 1.289 & -53.28 & 0.569 & 4.81 \\
$\mathrm{OK}_{3} @ \mathrm{GTY}$ & 2.482 & 2.561 & -56.23 & 1.011 & 4.79 \\
\hline
\end{tabular}

\subsection{Characteristics of Superalkali salts of Graphynes}

The atomic charges on the $\mathrm{OM}_{3}$ subunits of $\mathrm{OM}_{3} @ \mathrm{GYs}(\mathrm{M}=\mathrm{Li}, \mathrm{Na}$, and $\mathrm{K})$ were explored to analyze the electron transfer. Charge calculations were performed by using five methods including Merz-Kollman (MK), natural population analysis (NPA), atoms in molecules (AIM) ${ }^{54}$ atomic dipole moment corrected Hirshfeld $(\mathrm{ADCH})$ population, ${ }^{55}$ and Becke population ${ }^{52}$ (see Table S1 in the ESI). Here, the MK charges are selected to show the electron transfer, which are listed in Table 1. As shown in Table 1, the superalkali subunits exhibit positive MK charges in the range of $0.473-1.011|e|$, indicating that the doping superalkali donates electron to the GYs moiety. Molecular orbital (MO) analysis shows that the frontier MOs are the contributions of GYs (without $\mathrm{OM}_{3}$ contribution), also exhibiting the electron transfer. Since these superalkali-doped systems have similar MO character, the highest occupied molecular orbitals (HOMOs) of three $\mathrm{OLi}_{3}$-doped model systems are taken as examples and depicted in Figure 4. Therefore, the $\mathrm{OM}_{3} @ G Y s$ complexes are, in fact, superalkali salts of graphynes, and can be written as $\mathrm{OM}_{3}+@ \mathrm{GYs}^{-}$.
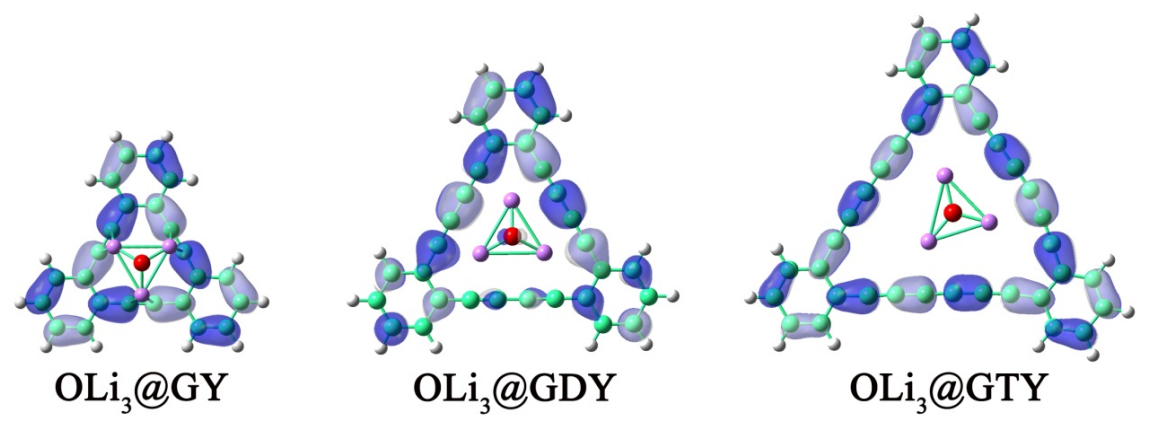

FIGURE 4 The highest occupied molecular orbitals (HOMOs) (isovalue $=0.02$ ) of $\mathrm{OLi}_{3}$-doped GY/GDY/GTY

Table 1 also collects the interaction energies $(E$ int $)$ between $\mathrm{OM}_{3}$ and GYs. From Table 1, all systems exhibit remarkably large $E$ int values ranging from -34.97 to $-61.15 \mathrm{kcal} \mathrm{mol}^{-1}$, indicating that these salts possess high stability. Previous studies have shown that the alkali metal cation-GY anion interaction strength is related to the size of the model GY systems. ${ }^{56} \mathrm{~A}$ similar situation occurs in our system. For example, the varying order of $E$ int is $-47.18\left(\mathrm{OLi}_{3}+\mathrm{GY}^{-}\right)<-53.00\left(\mathrm{OLi}_{3}+@ \mathrm{GDY}^{-}\right)<-61.15 \mathrm{kcal} \mathrm{mol}^{-1}\left(\mathrm{OLi}_{3}+@ \mathrm{GTY}^{-}\right)$, indicating that the pore size of the graphyne is an influencing factor on the stability for such systems. The more acetylene units are involved, the higher the stability of the complex salts. In particular, three $\mathrm{OLi}_{3}{ }^{-}$ doped salts have the largest $E$ int values among three types of graphynes, respectively, demonstrating that the interactions between the $\mathrm{OLi}_{3}$ units and the graphynes are much stronger. Hence, the $\mathrm{OLi}_{3}{ }^{+} @ \mathrm{GTY}^{-}$ has the highest stability.

Additionally, the electronic stability of the complexes is associated with their vertical ionization potential (VIP). Table 1 shows that the VIP values of the $\mathrm{OM}_{3}{ }^{+} @ \mathrm{GYs}^{-}$salts are in the range of 4.25-4.83 eV, which are higher than those of electride Li@calix[4]pyrrole $(4.16 \mathrm{eV})$ and superalkali-based alkalides $\mathrm{M}_{3} \mathrm{O} \cdot \mathbf{1} \cdot \mathrm{K}$ $\left(\mathrm{M}=\mathrm{Li}, \mathrm{Na}, \mathrm{K} ; \mathbf{1}=\right.$ all-cis $-1,2,3,4,5,6$-hexafluorocyclohexane) $(3.088-3.275 \mathrm{eV}) .{ }^{57,58}$ The higher VIP values suggest that these superalkali salts of graphynes exhibit higher electronic stability. Besides, the VIPs of these $\mathrm{OM}_{3}+@ \mathrm{GYs}^{-}$salts are comparable to those of reported superalkali-doped $\mathrm{M}_{2} \mathrm{X} @ \mathrm{GDY}(\mathrm{M}=\mathrm{Li}, \mathrm{Na}$, 
$\mathrm{K}$ and $\mathrm{X}=\mathrm{F}, \mathrm{Cl}, \mathrm{Br})$ systems $(4.59-5.20 \mathrm{eV}) .{ }^{36}$ It could be observed that as the atomic number of alkali metals increases, the positive charge on $\mathrm{OM}_{3}$ in the $\mathrm{OM}_{3}+@ G \mathrm{Ss}^{-}$system gradually increases, while the corresponding VIP value gradually decreases. For example, the $\mathrm{M}$ charge varies in the order $0.473(\mathrm{M}=\mathrm{Li})$ $<0.589(\mathrm{M}=\mathrm{Na})<0.666|e|(\mathrm{M}=\mathrm{K})$, and the VIP order is $4.61(\mathrm{M}=\mathrm{Li})>4.52(\mathrm{M}=\mathrm{Na})>4.25 \mathrm{eV}$ $(\mathrm{M}=\mathrm{K})$ for $\mathrm{OM}_{3}+@ \mathrm{GDY}^{-}$(Table 1).

\subsection{Nonlinear optical (NLO) properties and absorption spectrums}

The NLO properties of the studied complexes have been explored by calculating their static first hyperpolarizabilities $\left(\beta_{0}\right)$, which are given in Table 2. As listed in Table 2, it is noticed that the $\beta_{0}$ values of GYs are less than $0.50 \mathrm{au}$, whereas the $\mathrm{OM}_{3}{ }^{+} @ \mathrm{GYs}^{-}$complexes show much larger $\beta$ o values in the range of 227-653420 au. Among the $\mathrm{OM}_{3}+@ \mathrm{GYs}^{-}$series, $\mathrm{OLi}_{3}+@ \mathrm{GTY}^{-}$has the largest $\beta_{0}$ value. Note that it has a unique structure where the $\mathrm{OLi}_{3}$ is coplanar $(d=0.000)$ with GTY.

To investigate whether the first hyperpolarizabilities of these doped systems depend upon the atomic number of $\mathrm{M}$ in superalkali unit and the pore size of graphyne subunit, the relationships between $\beta_{0}$ values and different superalkali unit as well as different sized graphyne are illustrated in Figure 5. For the $\mathrm{OM}_{3}+@ \mathrm{GY}^{-}$ complexes, the $\beta_{0}$ varies in the order $227(\mathrm{M}=\mathrm{Li})<4334(\mathrm{M}=\mathrm{K})<7952$ au $(\mathrm{M}=\mathrm{Na})$. Undoubtedly, the maximum $\beta$ o value belongs to $\mathrm{ONa}_{3}{ }^{+} @ \mathrm{GY}^{-}$. Upon the combination with $\mathrm{OM}_{3}$, the $\beta$ ovalue of GDY dramatically increases to $224425-278540$ au. Different from the case of $\mathrm{OM}_{3}{ }^{+} @ \mathrm{GY}^{-}$, the $\beta$ o value of $\mathrm{OM}_{3}+@ \mathrm{GDY}^{-}$has no clear dependence on the atomic number of M. Remarkably, $\mathrm{OLi}_{3}{ }^{+} @ \mathrm{GTY}^{-}$has the largest $\beta$ o value up to 653420 au among all the studied complexes (see Figure 5a), which is about 40 and 15 times as large as those of $\mathrm{ONa}_{3}+@ \mathrm{GTY}^{-}(16246 \mathrm{au})$ and $\mathrm{OK}_{3}+@ \mathrm{GTY}^{-}(43713 \mathrm{au})$, respectively. It indicates the important effect of the atomic number of $\mathrm{M}$ on $\beta$ o value of $\mathrm{OM}_{3}{ }^{+} @ \mathrm{GTY}^{-}(\mathrm{M}=\mathrm{Li}, \mathrm{Na}$, and $\mathrm{K})$.

Data in Table 2 and Figure $5 \mathrm{~b}$ display that the $\beta_{0}$ value increases quite rapidly in the order $\mathrm{OLi}_{3}+@ \mathrm{GY}^{-}<$ $\mathrm{OLi}_{3}+@ \mathrm{GDY}^{-}<\mathrm{OLi}_{3}+@ \mathrm{GTY}^{-}$, demonstrating that the effect of pore size of graphyne on the $\beta$ v value of $\mathrm{OM}_{3}+@ \mathrm{GYs}^{-}$is significant. Notably, the $\beta$ o value is enhanced by approximate 2880 -fold from 227 au $\left(\mathrm{OLi}_{3}+@ \mathrm{GY}^{-}\right)$to $653420 \mathrm{au}\left(\mathrm{OLi}_{3}+@ \mathrm{GTY}^{-}\right)$. Therefore, the selection of GTY with large pore is an effective strategy for enhancing the $\beta$ o of the $\mathrm{OLi}_{3}$-doped graphyne molecules. When $\mathrm{ONa}_{3}$ and $\mathrm{OK}_{3}$ are doped into GYs, the $\beta$ v values of the resulting complexes vary in the sequence of $\mathrm{OM}_{3}+@ \mathrm{GY}^{-}<\mathrm{OM}_{3}+\mathrm{GTY}^{-}<$ $\mathrm{OM}_{3}{ }^{+} @ \mathrm{GDY}^{-}(\mathrm{M}=\mathrm{Na}$ and $\mathrm{K})$. The results suggest that the medium-sized GDY should be a better match for $\mathrm{OM}_{3}(\mathrm{M}=\mathrm{Na}$ and $\mathrm{K})$ in forming complexes with higher NLO response.

TABLE 2 The first hyperpolarizabilities $\beta$ o (au), transition energies $\Delta E(\mathrm{eV})$, oscillator strengths $f$ 0 , and difference of dipole moment $\Delta \mu$ (Debye) between ground state and crucial excited state of the GY/GDY/GTY and $\mathrm{OM}_{3} @(\mathrm{GY} / \mathrm{GDY} / \mathrm{GTY})(\mathrm{M}=\mathrm{Li}, \mathrm{Na}$, and $\mathrm{K})$

\begin{tabular}{|c|c|c|c|c|}
\hline System & $\beta_{0}$ & $\Delta E$ & $f_{0}$ & $\Delta \mu$ \\
\hline GY & 0.07 & 4.504 & 1.0913 & 1.100 \\
\hline $\mathrm{OLi}_{3} @ \mathrm{GY}$ & 227 & 1.361 & 0.1060 & 0.647 \\
\hline $\mathrm{ONa}_{3} @ \mathrm{GY}$ & 7952 & 1.343 & 0.1105 & 2.936 \\
\hline $\mathrm{OK}_{3} @ \mathrm{GY}$ & 4334 & 1.307 & 0.1050 & 1.650 \\
\hline GDY & 0.47 & 3.763 & 0.9915 & 0.646 \\
\hline $\mathrm{OLi}_{3} @ \mathrm{GDY}$ & 265248 & 2.217 & 0.1910 & 2.698 \\
\hline $\mathrm{ONa}_{3} @ \mathrm{GDY}$ & 224425 & 2.110 & 0.1615 & 1.690 \\
\hline $\mathrm{OK}_{3} @ \mathrm{GDY}$ & 278540 & 2.061 & 0.1687 & 0.564 \\
\hline GTY & 0.18 & 3.526 & 0.6889 & 0.499 \\
\hline $\mathrm{OLi}_{3} @ \mathrm{GTY}$ & 653420 & 0.692 & 0.2156 & 8.687 \\
\hline $\mathrm{ONa}_{3} @ \mathrm{GTY}$ & 16246 & 0.604 & 0.2240 & 1.557 \\
\hline $\mathrm{OK}_{3} @ \mathrm{GTY}$ & 43713 & 0.613 & 0.2126 & 0.673 \\
\hline
\end{tabular}

Taking into account the effects of atomic number of $\mathrm{M}$ in superalkali unit and pore size of graphyne on 
first hyperpolarizabilities, we conclude that the combination of superalkali $\mathrm{OLi}_{3}$ and GTY with a large pore is more advantageous for designing superalkali salts of graphynes with high stability and excellent NLO properties. Besides, the large $\beta_{0}$ value of $\mathrm{OLi}_{3}+@ \mathrm{GTY}^{-}$is a new record for superalkali/superalkaline-earth doped graphynes. The above results may provide important references for further studies of such graphynes and their derivatives.
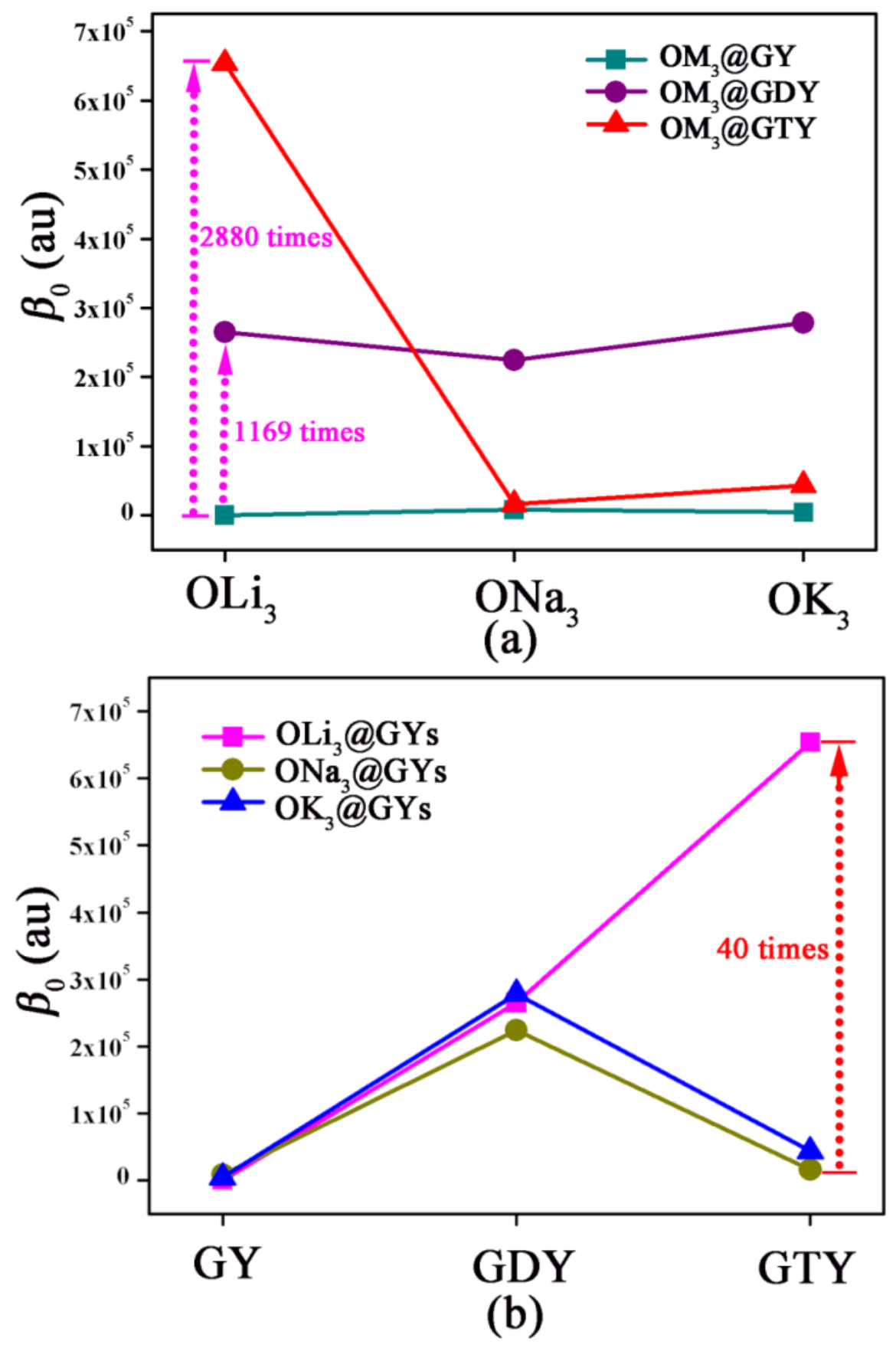

FIGURE 5 Effects of the atomic number of alkali atom in superalkali $\mathrm{OM}_{3}$ unit (a) and the pore size of the graphyne (b) on the first hyperpolarizability $\left(\beta_{0}\right)$, respectively 
The rough two-level model ${ }^{59}$ can help to understand the reason why the introduction of superalkali dopant can effectively increase the $\beta$ o value of GYs. This model can be expressed as:

$$
\beta_{0} \propto \frac{\mu \bullet f_{0}}{E^{3}}(4)
$$

where $\Delta E, f_{0}$, and $\Delta \mu$ are the transition energy, the oscillator strength, and the difference of the dipole moment between the ground state and the crucial excited state, respectively. Since the static $\beta{ }_{0}$ inversely varies with the third power of $\Delta E$, low $\Delta E$ is usually a decisive factor for large $\beta$ o values of molecules. Meanwhile, the $f_{0}$ and $\Delta \mu$ are also important influencing factors on $\beta_{0}$ for some compounds. ${ }^{60}$ The TD-DFT calculations at the CAM-B3LYP/6-31+G(d) level were performed to obtain the crucial excited states of the studied systems, and the above three parameters are listed in Table 2. The pristine GY/GDY/GTY molecules with very small $\beta$ o values $(0.07-0.47 \mathrm{au})$ have high $\Delta E$ values $(4.504,3.763$, and $3.526 \mathrm{eV}$, respectively). Conversely, the introduction of $\mathrm{OM}_{3}$ can bring much lower $\Delta E$ values $\left(1.307-1.361\right.$ for $\mathrm{OM}_{3}+@ \mathrm{GY}^{-}, 2.061-$ 2.217 for $\mathrm{OM}_{3}+@ \mathrm{GDY}^{-}$, and $0.604-0.692 \mathrm{eV}$ for $\mathrm{OM}_{3}{ }^{+} @ \mathrm{GTY}^{-}$) and large $\beta$ o values. These results may help us understand the significant superalkali doping effect on $\beta_{0}$ values of graphynes. Nevertheless, the $\Delta E$ value is not the only factor that determines the $\beta_{0}$ of a system. It is necessary to further consider the influence of $f_{0}$ and $\Delta \mu$ on the first hyperpolarizability. From Table 2 , the $f_{0}$ values of each superalki-doped series are close to each other, so they are not the crucial factor that results in the difference of $\beta$ o among the studied compounds. It should be noted, however, that the systems with large $\Delta \mu$ also present relatively large NLO responses. For instance, the computed $\Delta \mu$ value of $\mathrm{OLi}_{3}{ }^{+} @ \mathrm{GTY}^{-}(8.687$ Debye) is much larger than those of $\mathrm{ONa}_{3}+@ \mathrm{GTY}^{-}\left(1.557\right.$ Debye) and $\mathrm{OK}_{3}{ }^{+} @ \mathrm{GTY}^{-}(0.673$ Debye), indicating that the $\Delta \mu$ value may be the main reason for the largest $\beta$ o value of $\mathrm{OLi}_{3}{ }^{+} @ \mathrm{GTY}^{-}$among these salts.

The dominant electron transitions (the transition with relatively low transition energy and high oscillator strength) of $\mathrm{OM}_{3}+@(\mathrm{GY} / \mathrm{GDY} / \mathrm{GTY})^{-}$also help to further explore the reason why the complexes have large $\beta$ 0 values (see Figure 6). Now, we focus on the nature of crucial transition of the $\mathrm{OM}_{3}+@ \mathrm{GTY}^{-}$series. For the $\mathrm{OM}_{3}+@ \mathrm{GTY}^{-}$series, the crucial transition is all from the highest occupied molecular orbital (HOMO) to the lowest unoccupied molecular orbital (LUMO). Their electron clouds of HOMOs are almost of the same shape, which are mainly centralized on the large GTY surface. The LUMOs of $\left(\mathrm{ONa}_{3} / \mathrm{OK}_{3}\right)^{+} @ \mathrm{GTY}^{-}$have the electron cloud distributions close to those of HOMOs. Therefore, the charge transfer of $\left(\mathrm{ONa}_{3} / \mathrm{OK}_{3}\right)^{+} @ \mathrm{GTY}^{-}$is small and the corresponding $\Delta \mu$ values are small in the electron transitions. However, the electron cloud distribution of LUMO of $\mathrm{OLi}_{3}+@ \mathrm{GTY}^{-}$lacks a part in orange box in Figure 6. Therefore, $\mathrm{OLi}_{3}+@ \mathrm{GTY}^{-}$ has a large charge transfer from the ground state to the crucial transition state, resulting in the largest $\Delta \mu$. 

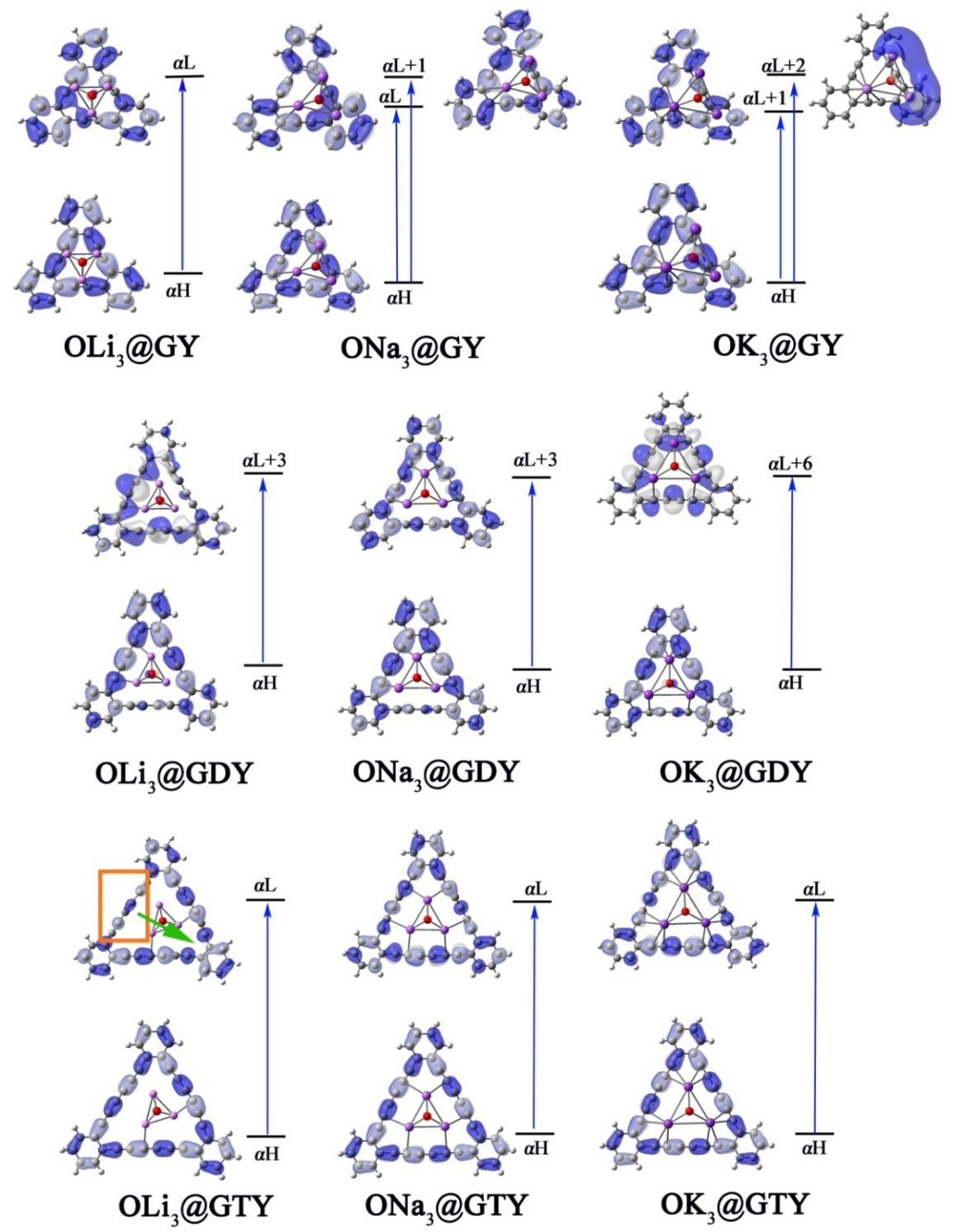

FIGURE 6 Molecular orbitals corresponding to the dominant electron transitions of the $\mathrm{OM}_{3} @ \mathrm{GYs}$ complexes. $\mathrm{H}$ and $\mathrm{L}$ represent the highest occupied molecular orbital (HOMO) and the lowest unoccupied molecular orbital (LUMO), respectively

It is well-known that for the Li@calix[4]pyrrole electride with large $\beta_{0}$ value, ${ }^{58}$ the electron involved in the critical excited state is in the HOMO, which is derived from the diffuse excess electron cloud of the alkali atom. This means that the excess electron makes a significant contribution to the large hyperpolarizability of electride. It can be found from Figure 6 that the electron clouds of HOMO and crucial excited states of $\mathrm{OM}_{3} @(\mathrm{GDY} / \mathrm{GTY})$ are mainly distributed over the (GDY/GTY $)^{-}$moiety. Therefore, we speculate that (GDY/GTY $)^{-}$unit is the main source of the large first hyperpolarizability value of the system. Obviously, electronic transition characteristics of the topic systems are different from those of electride molecules with excess electrons.

To show the contribution of (GDY/GTY $)^{-}$to the first hyperpolarizability of $\mathrm{OM}_{3}{ }^{+} @(\mathrm{GDY} / \mathrm{GTY})^{-}$, we take $\mathrm{OLi}_{3}+@(\mathrm{GDY} / \mathrm{GTY})^{-}$as an example and calculate the first hyperpolarizabilities of $(e @ \mathrm{GDY})^{-}$and 
$(e @ \mathrm{GTY})^{-}$. The structures of $(e @ \mathrm{GDY})^{-}$and $(e @ \mathrm{GTY})^{-}$were obtained by removing $\mathrm{OLi}_{3}+$ from the optimized structures of $\mathrm{OLi}_{3}{ }^{+} @ \mathrm{GDY}^{-}$and $\mathrm{OLi}_{3}+@ \mathrm{GTY}^{-}$, respectively. Subsequently, the $\beta$ values of the $(e$ @GDY $)^{-}$and ( $e$ @GTY $)^{-}$anions were calculated to be 483232 and 711447 au at the CAM-B3LYP/6-31+G(d) level. Clearly, the large first hyperpolarizabilities of $\mathrm{OLi}_{3}{ }^{+} @ \mathrm{GDY}^{-}(265248 \mathrm{au})$ and $\mathrm{OLi}_{3}{ }^{+} @ \mathrm{GTY}^{-}(653420$ $\mathrm{au}$ ) are almost from the contributions of the graphyne anion units.

The spatial contribution of the electrons to the NLO response of $\mathrm{OLi}_{3} @(G D Y / G T Y)$ is explored in terms of first hyperpolarizability density. ${ }^{61}$ Electron density $\rho(r, F)$ can be written as Taylor expansion with respect to the externally applied electric field $F$ :

$\rho(r, F)=\rho^{(0)}(r)+\sum_{j} \rho_{j}^{(1)}(r) F_{j}+\frac{1}{2 !} \sum_{j} \sum_{k} \rho_{\mathrm{jk}}^{(2)}(r) F_{j} F_{k}+\cdots(5)$

From above equation and expansion formula of dipole moment in power of the field, a component of first hyperpolarizability can be expressed by:

$\beta_{\mathrm{ijk}}=-\frac{1}{2 !} \int r_{i} \rho_{\mathrm{jk}}^{(2)}(r) d r^{3}(6)$

where

$\rho_{\mathrm{jk}}^{(2)}(r)=\left.\frac{\partial^{2} \rho(r)}{\partial F_{j} \partial F_{k}}\right|_{F=0}(7)$

The electron density was calculated at the CAM-B3LYP/6-31+G(d) level using $F=0.003$ au. We focus on the $\beta_{\xi \xi \xi}$ and $\beta_{\psi \psi \psi}$ components which are the important components of $\beta_{0}$ value of $\mathrm{OLi}_{3} @(\mathrm{GDY} / \mathrm{GTY})$.

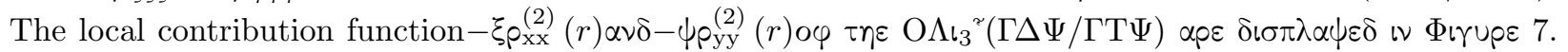

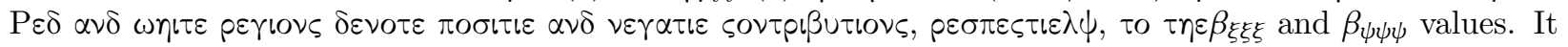
can be seen that the main contribution to the first hyperpolarizability comes from GDY and GTY moieties. The graphs of $-x \rho_{\mathrm{xx}}^{(2)}(r)$ and $-y \rho_{\mathrm{yy}}^{(2)}(r)$ for $\mathrm{OLi}_{3} @$ GDY show the fact that the positive local contribution region is larger than the negative part. This is the reason why the $\mathrm{OLi}_{3} @$ GDY has considerable positive $\beta_{\xi \xi \xi}$ $(266941 \mathrm{au})$ and $\beta_{\psi \psi \psi}(280948 \mathrm{au})$ values. For $\mathrm{OLi}_{3} @ \mathrm{GTY}$, the $-x \rho_{\mathrm{xx}}^{(2)}(r)$ function diagram shows that the positive contribution area is much larger than the negative part, while the opposite result is observed for the-y $\rho_{\mathrm{yy}}^{(2)}(r)$ function. Compared with the- $y \rho_{\mathrm{yy}}^{(2)}(r)$, the $-x \rho_{\mathrm{xx}}^{(2)}(r)$ shows a relatively larger regional scope for both positive and negative contributions. Thus, the OLi ${ }_{3} @$ GTY possesses large positive $\beta_{\xi \xi \xi}(521577 \mathrm{au})$ and relatively small negative $\beta_{\psi \psi \psi}(-195843 \mathrm{au})$ values. 


\section{(a)OLi $@$ @GDY}
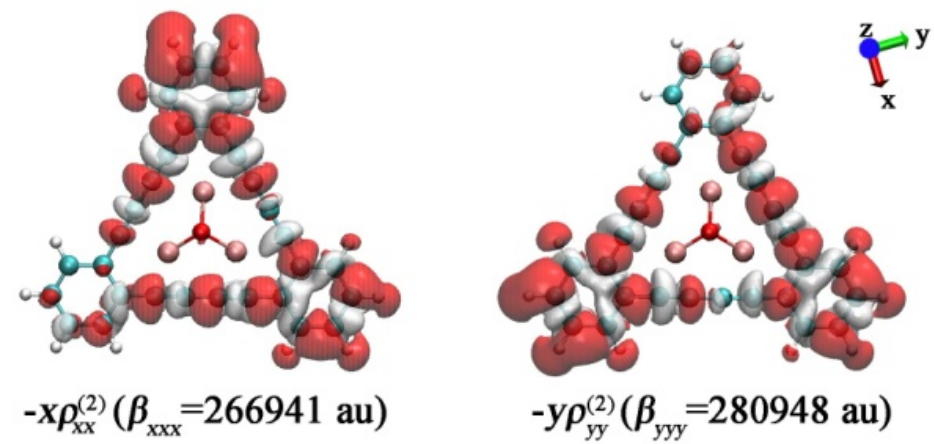

\section{(b)OLi ${ }_{3}$ GTY}
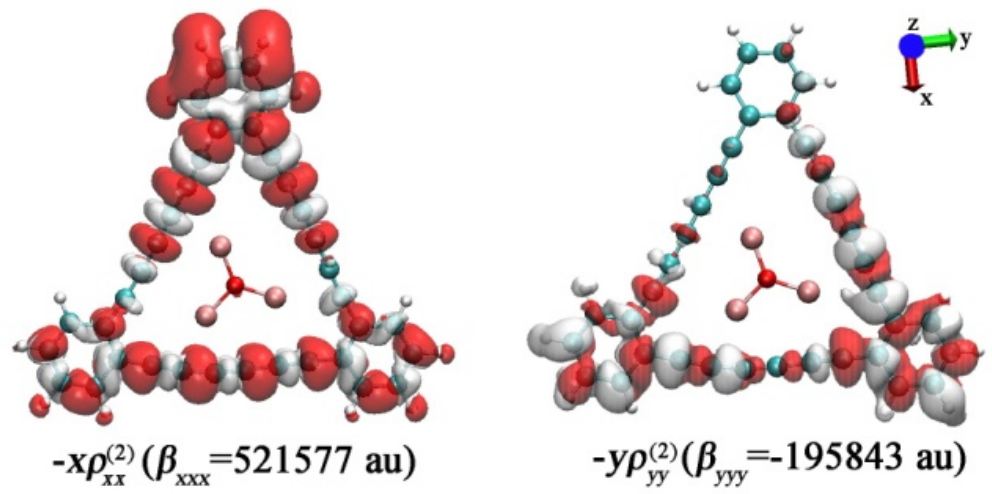

FIGURE 7 Plots of $-x \rho_{\mathrm{xx}}^{(2)}(r)$ and $-y \rho_{\mathrm{yy}}^{(2)}(r)$ for $\mathrm{OLi}_{3} @(\mathrm{GDY} / \mathrm{GTY})$

It is interesting to compare the $\beta_{0}$ values of our superalkali salts of graphynes with the previously reported superatom doped complexes. Theoretical studies on the three series of $\mathrm{AM}_{3} @ G D Y, \mathrm{M}_{2} \mathrm{X} @ \mathrm{GDY}$, and $\mathrm{M}_{3} \mathrm{~F} @ \mathrm{GDY}$ complexes show that intramolecular charge-transfer mechanism in the D-A system can play a key role in enhancing nonlinear optical properties. ${ }^{32,35,36} \mathrm{~A}$ comparison between $\mathrm{OM}_{3}{ }^{+} @ \mathrm{GDY}^{-}\left(\beta_{0}=\right.$ $\left.2.2 \times 10^{5}-2.8 \times 10^{5} \mathrm{au}\right)$ and $\mathrm{AM}_{3} @ \mathrm{GDY}(\mathrm{AM}=\mathrm{Li}, \mathrm{Na} \text {, and } \mathrm{K})^{32}\left(\beta_{0}=9.2 \times 10^{3}-1.6 \times 10^{5} \mathrm{au}\right)$ indicates that doping superalkali $\mathrm{OM}_{3}$ may be more beneficial to enhance the NLO response than $\mathrm{AM}_{3}$. The computational results of Shehzadi et al. ${ }^{36}$ suggested that the $\beta_{0}$ values of superalkalis doped graphdiyne $\left[\mathrm{M}_{2} \mathrm{X} @ \mathrm{GDY}\right.$ (M $=\mathrm{Li}, \mathrm{Na}, \mathrm{K}$ and $\mathrm{X}=\mathrm{F}, \mathrm{Cl}, \mathrm{Br})]$ are in the range of $6.2 \times 10^{3}-6.6 \times 10^{4} \mathrm{au}$, which are much lower than those $\left(2.2 \times 10^{5}-2.8 \times 10^{5} \mathrm{au}\right)$ of $\mathrm{OM}_{3}+@ \mathrm{GDY}^{-}$. Literatures reported ${ }^{19,62,63}$ that ionization energy of $\mathrm{OM}_{3}$ is lower than the corresponding $\mathrm{M}_{2} \mathrm{~F}(\mathrm{M}=\mathrm{Li}, \mathrm{Na}$, and $\mathrm{K})$. Therefore, superalkali $\mathrm{OM}_{3}$ can induce greater charge transfer in the doped compounds than $\mathrm{M}_{2} \mathrm{~F}$ does, and consequently, $\mathrm{OM}_{3}$, as a dopant, can increase the $\beta$ ${ }_{0}$ value of GDY more effectively. Besides, the excellent NLO response of $\mathrm{OM}_{3}+@ \mathrm{GDY}^{-}$is strongly superior to that of superalkaline-earth metal doped GDY $\left(\beta_{0}=1.1 \times 10^{4} \mathrm{au}\right)$, and even preferable to those of cationic $\mathrm{M}_{3} \mathrm{~F} @ \mathrm{GDY}^{+}(\mathrm{M}=\mathrm{Li}, \mathrm{Na}$, and $\mathrm{K})\left(1.1 \times 10^{5}-1.6 \times 10^{5} \mathrm{au}\right){ }^{35}$ This means that using superalkali $\mathrm{OM}_{3}$ as a dopant may be a better choice. Noteworthily, the $\beta_{0}$ values of $\mathrm{OM}_{3}{ }^{+} @(\mathrm{GDY} / \mathrm{GTY})^{-}$are much larger than those of previously reported superalkali $\left(\mathrm{M}_{3} \mathrm{O}^{+}, \mathrm{M}=\mathrm{Li}, \mathrm{Na}\right.$, and $\mathrm{K}$ ) supported graphene nanoflakes (GR) $\left(8.4 \times 10^{2}-3.1 \times 10^{3} \mathrm{au}\right),{ }^{64}$ which indicates that the largely $\pi$-conjugated graphyne is superior to graphene in producing complexes with large $\beta$ o values.

Besides large NLO responses, excellent NLO molecules should have favored transparency spectral ranges 
(infrared or deep-ultraviolet bands) of electronic absorption spectra, which cannot be ignored in practice. The ultraviolet-visible (UV-vis) absorption spectra of the systems are obtained by using the TD-CAMB3LYP method. As one can observe from Figure 8, both pristine GDY and GTY have maximum absorption in ultraviolet region (wavelength $<400 \mathrm{~nm}$ ). However, we can find that, upon the introduction of superalkalis, the strongest absorption peak shifts from short wavelength to long wavelength. Besides, the main absorption region of $\mathrm{OM}_{3}+\mathrm{GDY}^{-}$is from 250 to $1000 \mathrm{~nm}$. That is to say, there are obvious absorption peaks within the visible or near visible region. The $\mathrm{OM}_{3}+@ \mathrm{GTY}^{-}$complexes have visible and infrared absorption regions at wavelength $>300 \mathrm{~nm}$. Obviously, both the $\mathrm{OM}_{3}{ }^{+} @ \mathrm{GDY}^{-}$and $\mathrm{OM}_{3}{ }^{+} @ \mathrm{GTY}^{-}$complexes have a deepultraviolet transparent region at wavelength [?] $200 \mathrm{~nm}$, demonstrating that they could be used as new candidates for deep-ultraviolet NLO materials.

Overall, all of these superalkali salts of graphynes with high structural stability not only have excellent NLO response but also have a satisfactory working waveband in the deep-UV region, which may be a new member of the high-performance NLO material family. 

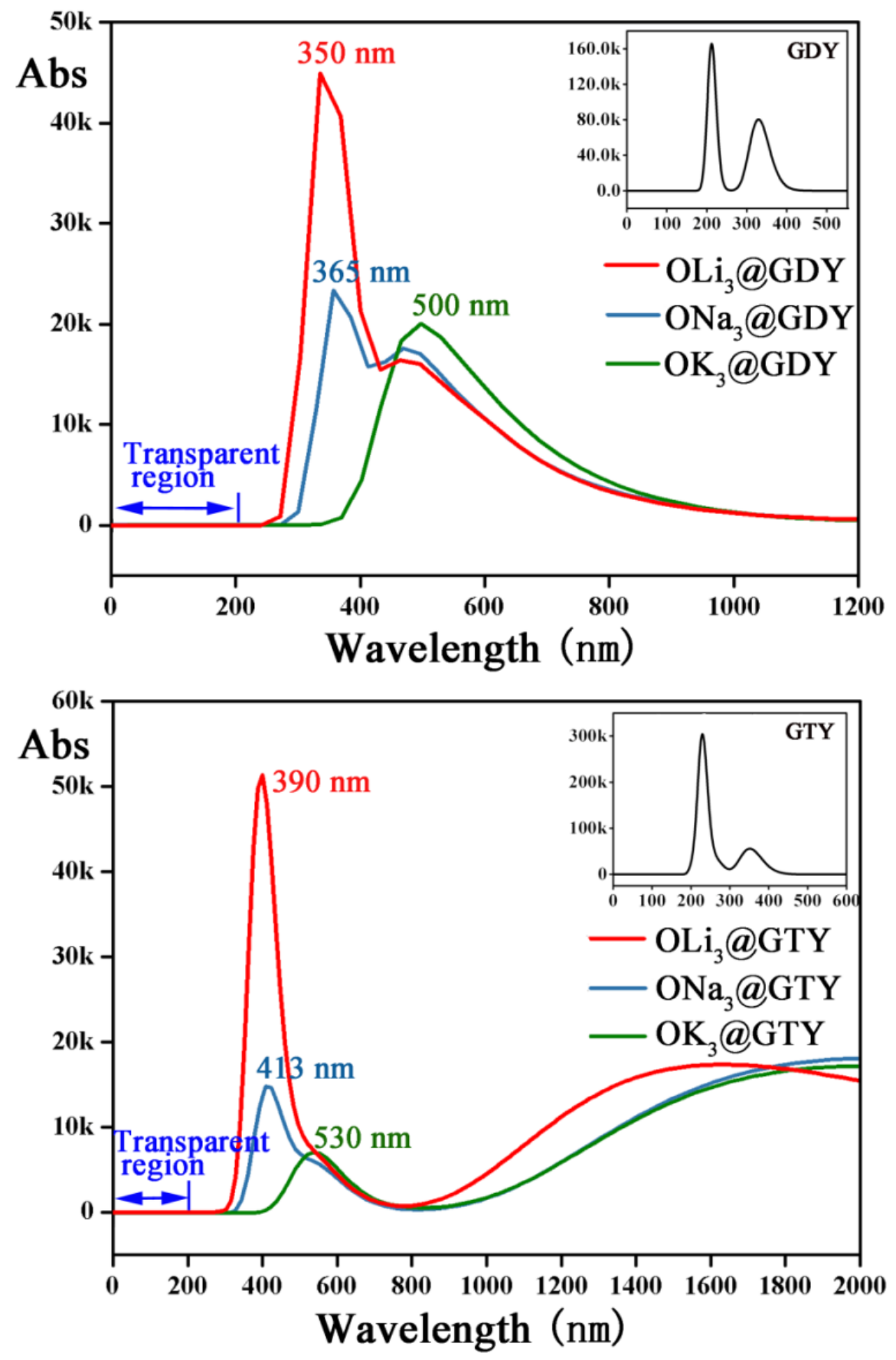

FIGURE 8 The computed electronic spectra of the different systems

\section{CONCLUSIONS}

To find new high-performance deep-UV NLO molecules, the superalkalis $\left(\mathrm{OLi}_{3}, \mathrm{ONa}_{3}\right.$, and $\left.\mathrm{OK}_{3}\right)$ and graphynes (GY/GDY/GTY) were combined to design superalkali salts of graphynes with considerable nonlinear optical (NLO) properties. Besides, the dependence of first hyperpolarizability of the resulting compounds 
on superalkali atom and pore size of graphyne were explored. The superalkali-doped complexes have high structural stability, which can be reflected by large interaction energies between the superalkali and graphyne units, ranging from -34.97 to $-61.15 \mathrm{kcal} \mathrm{mol}^{-1}$. The atomic charge and frontier molecular orbital studies reveal that these superalkali-doped complexes are superalkali salts of graphynes. The superalkali and (pore) size of the graphyne unit play extremely important roles in enhancing $\beta$ o values of the doped complexes. Based on the best match between size of superalkalis and pore size of graphynes, $\mathrm{OLi}_{3}+@ \mathrm{GTY}^{-}$exhibits the $\beta_{0}$ value $(653420 \mathrm{au})$ of new record for atom/superatom doped graphynes. Besides, these molecules have a working waveband in the deep-ultraviolet region. Hence, these superalkali salts of graphynes are new deep-UV NLO molecules with large second order NLO response.

\section{ACKNOWLEDGEMENTS}

This work was supported by National Natural Science Foundation of China (21373131 and 21573089), Shanxi Province Science Foundation for Youths (201801D221066), and the 1331 Engineering of Shanxi Province.

\section{REFERENCES}

${ }^{1}$ I. D. L. Albert, T. J. Marks and M. A. Ratner, J. Am. Chem. Soc. , 1997,119 , 6575-6582.

${ }^{2}$ N. Hou, F. Y. Du and H. S. Wu, Org. Electron, 2019, 68, 9-14.

${ }^{3}$ C. Wu, G. Yang, M. G. Humphrey and C. Zhang, Coordin. Chem. Rev. , 2018,375 , 459-488.

${ }^{4}$ B. Zhang, G. Shi, Z. Yang, F. Zhang and S. Pan, Angew. Chem. Int. Ed., 2017,56 , 3916.

${ }^{5}$ W. Y. Wang, L. Wang, N. N. Ma, C. L. Zhu and Y. Q. Qiu, Dalton Trans. , 2015,44, 10078-10088.

${ }^{6}$ T. Kaino, T. Kurihara, K.-i. Kubodera and H. Kanbara, ACS Symp. Ser. , 1991,455 , 704-721.

7 M. Nakano, T. Minami, K. Yoneda, S. Muhammad, R. Kishi, Y. Shigeta, T. Kubo, L. Rougier, B. Champagne and K. Kamada, J. Phys. Chem. Lett., 2011,2 , 1094-1098.

8 S. R. Marder, D. N. Beratan and L. T. Cheng, Science, 1991, 252, 103-106.

${ }^{9}$ B. J. Coe, S. P. Foxon, E. C. Harper, H. Madeleine, R. James, C. A. Swanson, B. S. Brunschwig, C. Koen, F. Edith and G. Javier, J. Am. Chem. Soc., 2010, 132, 1706-1723.

10 T. Nicolas, F. Christophe, L. Isabelle, Z. Joseph, L. Toupet, L. B. Hubert and M. Olivier, J. Am. Chem. Soc. , 2005, $127,13474$.

11 T. G. Zhang, Y. Zhao, I. Asselberghs, A. Persoons, K. Clays and M. J. Therien, J. Am. Chem. Soc., 2005, 127, 9710-9720.

12 R. L. Zhong, H. L. Xu, Z. R. Li and Z. M. Su, J. Phys. Chem. Lett. , 2015,6 , 612-619.

${ }^{13}$ G. T. Yu, X. R. Huang, S. C. Li and W. Chen, Int. J. Quantum Chem. , 2015,115, 671-679.

${ }^{14}$ W. Chen, Z. R. Li, D. Wu, F. L. Gu, X. Y. Hao, B. Q. Wang, R. J. Li and C. C. Sun,J. Chem. Phys., 2004, 121, 10489-10494.

${ }^{15}$ Y. Li, Z. R. Li, D. Wu, R. Y. Li, X. Y. Hao and C. C. Sun, J. Phys. Chem. B , 2004,35, 3145-3148.

16 S. Banerjee and S. K. Pati, Chem. Commun. 2016, 52, 8381-8384.

17 W. M. Sun, X. H. Li, D.Wu, Y. Li, H. M. He, Z. R. Li, J. H. Chen and C. Y. Li,Dalton Trans., 2016, 45 , 7500-7509.

18 N. Hou, Y. Y. Wu, H. S. Wu and H. M. He, Synthetic Met. , 2017, 232, 39-45.

19 G. L. Gutsev and A. Boldyrev, Chem. Phys. Lett. , 1982, 92 , 262-266.

20 S. Khanna and P. Jena, Phys. Rev. B , 1995, 51, 13705-13716. 
21 R. H. Baughman, H. Eckhardt and M. Kertesz, J. Chem. Phys. , 1987, 87 , 6687-6699.

22 C. Huang, Y. Li, N. Wang, Y. Xue, Z. Zuo, H. Liu and Y. Li, Chem. Rev. , 2018,118 , 7744-7803.

23 T. Lin and J. Wang, ACS Appl. Mater. Interfaces , 2018, 11 , 2638-2646.

${ }^{24}$ G. Li, Y. Li, H. Liu, Y. Guo, Y. Li and D. Zhao, Chem. Commun. , 2010, 46 , 3256-3258.

25 J. Li, X. Gao, B. Liu, Q. Feng, X. B. Li, M. Y. Huang, Z. Liu, J. Zhang, C. H. Tung and L. Z. Wu, J. Am. Chem. Soc. , 2016, 138 , 3954-3957.

26 J. Kang, Z. Wei and J. Li, ACS Appl. Mater. Interfaces , 2018, 11 , 2692-2706.

27 S. Chandra Shekar and R. S. Swathi, J. Phys. Chem. C , 2014, 118 , 4516-4528.

28 H. Zhang, X. Zhao, Z. Meng, Y. Luo, G. Li and M. Zhao, J. Phys. D: Appl. Phys. , 2013,46 , 5307.

29 Z. Chen, C. Molina-Jirón, S. Klyatskaya, F. Klappenberger and M. Ruben, Ann. Phys. (Berlin ), 2017, $529,1700056$.

${ }^{30}$ H. Chakraborti,Spectrochimi. Acta A , 2016, 153 , 226-230.

31 S. Kamalinahad, M. Solimannejad and E. Shakerzadeh, Bull. Chem. Soc. Jpn. , 2016,89 , $692-699$.

32 X. Li, J. Mater. Chem. C , 2018, 6 , 7576-7583.

33 X. Li and S. Li,J. Mater. Chem. C , 2019, 7 , 1630-1640

34 X. Li, J. Mol. Liq. , 2019, 277 , 641-645.

35 X. Li and J. Lu,Phys. Chem. Chem. Phys. , 2019, 21, 13165.

${ }^{36}$ K. Shehzadi, K. Ayub and T. Mahmood, Appl. Surf. Sci. , 2019, 492 , 255-263.

37 N. Narita, S. Nagai, S. Suzuki and K. Nakao, Phys. Rev. B , 1998, 58 , 11009.

38 C. H. Wu, H. Kudo and H. R. Ihle, J. Chem. Phys ., 1979, 70 , 1815.

39 A. Goldbach, F. Hensel and K. Rademann, Int. J. Mass Spectrom Ion Process , 1995,148, L5-L9.

40 O. Hampe, G. M. Koretsky, M. Gegenheimer, C. Huber, M. M. Kappes and J. Gauss, J. Chem. Phys. , 1997, 107 , 7085-7095.

41 J. J. Wang, Z. J. Zhou, Y. Bai, Z. B. Liu, Y. Li, D. Wu, W. Chen, Z. R. Li and C. C. Sun, J. Mater. Chem. , 2012, 22 , 9652-9657.

42 Y. D. Song, L. Wang and Q. T. Wang, Optik , 2018, 65 , 319-331.

43 J. M. Mai, S. D.Gong, N.Li, Q.Luo and Z. R. Li, Phys. Chem. Chem. Phys. , 2015,17 , $28754-25864$.

44 A. Omidvar,Inorg. Chem. , 2018, 57 , 9335-9347.

45 B. H. Besler, K. M. M. Jr and P. A. Kollman, J. Comput. Chem. , 1990, 11 , 431-439.

46 S. F. Boys and F. Bernardi, Mol. Phys., 1970, 19 , 553-566.

47 T. Yanai, D. P. Tew and N. C. Handy, Chem. Phys. Lett. , 2004, 393 , 51-57.

${ }^{48}$ M. J. Peach, T. Helgaker, P. Sałek, T. W. Keal, O. B. Lutnaes, D. J. Tozer and N. C. Handy, Phys. Chem. Chem. Phys. , 2006, 8 , 558-562.

49 C. Tu, G. Yu, G. Yang, X. Zhao, W. Chen, S. Li and X. Huang, Phys. Chem. Chem. Phys. , 2014, 16 , 1597-1606.

${ }^{50}$ M. J. Frisch, G. W. Trucks, H. B. Schlegel, G. E. Scuseria, M. A. Robb, J. R. Cheeseman, G. Scalmani, V. Barone, B. Mennucci, G. A. Petersson, H. Nakatsuji, M. Caricato, X. Li, H. P. Hratchian, A. F. Izmaylov, 
G. Z. J. Bloino, J. L. Sonnenberg, M. Hada, M. Ehara, K. Toyota, R. Fukuda, J. Hasegawa, M. Ishida, T. Nakajima, Y. Honda, O. Kitao, H. Nakai, T. Vreven, J. A. Montgomery, J. E. Peralta, F. Ogliaro, M. Bearpark, J. J. Heyd, E. Brothers, K. N. Kudin, V. N. Staroverov, T. Keith, R. Kobayashi, J. Normand, K. Raghavachari, A. Rendell, J. C. Burant, S. S. Iyengar, J. Tomasi, M. Cossi, N. Rega, J. M. Millam, M. Klene, J. E. Knox, J. B. Cross, V. Bakken, C. Adamo, J. Jaramillo, R. Gomperts, R. E. Stratmann, O. Yazyev, A. J. Austin, R. Cammi, C. Pomelli, J. W. Ochterski, R. L. Martin, K. Morokuma, V. G. Zakrzewski, G. A. Voth, P. Salvador, J. J. Dannenberg, S. Dapprich, A. D. Daniels, O. Farkas, J. B. Foresman, J. V. Ortiz, J. Cioslowski and D. J. Fox, Gaussian 09 , Revision E.01, Gaussian, Inc., Wallingford CT, 2013.

${ }^{51}$ R. Dennington, T. Keith and J. Millam, GaussView, version 5 , Semichem, Inc., Shawnee Mission, KS, 2009 .

52 T. Lu and F. W. Chen, J. Comput. Chem., 2012, 33, 580-592.

53 A. D. W. Humphrey and K. Schulten, J. Mol. Graph. , 1996, 14 , 33-38.

${ }^{54}$ R. F. W. Bader, Clarendon Press, Oxford, 1990.

55 T. Lu and F. Chen, J. Theor. Comput. Chem. , 2012, 11, 163-183.

${ }^{56}$ S. C. Shekar and R. S. Swathi, J. Phys. Chem. C , 2015, 119 , 8912.

57 W. M. Sun, B. L. Ni, D. Wu, J. M. Lan, C. Y. Li, Y. Li and Z. R. Li, Organometallics , 2017, 36 , 3352-3359.

${ }^{58}$ W. Chen, Z. R. Li, D. Wu, Y. Li, C. C. Sun and F. L. Gu, J. Am. Chem. Soc., 2005, 127, 10977-10981.

59 J. L. Oudar,J. Chem. Phys., 1977, 67 , 446-457.

${ }^{60}$ W. M. Sun, D. Wu, Y. Li, J. Y. Liu, H. M. He and Z. R. Li, Phys. Chem. Chem. Phys. , 2015, 17 , 4524-4532.

${ }^{61}$ M. Nakano, I. Shigemoto, S. Yamada and K. Yamaguchi, J. Chem. Phys. , 1995,103, 4175-4170.

${ }^{62}$ S. R. Velickovic, F. M. Veljkovic, A. A. Peric-Grujic, B. B. Radak and M. V. Veljkovic, Rapid Commun. Mass Sp. , 2011, 25 , 2327-2332.

63 J. Tong, Y. Li, D. Wu and Z. J. Wu, Chem. Phys. Lett. , 2013, 575, 27-31.

${ }^{64}$ D. Chakraborty and P. K. Chattaraj, Phys. Chem. Chem. Phys. , 2016, 18 , 18811. 